\title{
Patterns of breast cancer radiotherapy practices among Saudi radiation oncologists
}

\author{
Reem K. Ujaimi, MD, FRCPC.
}

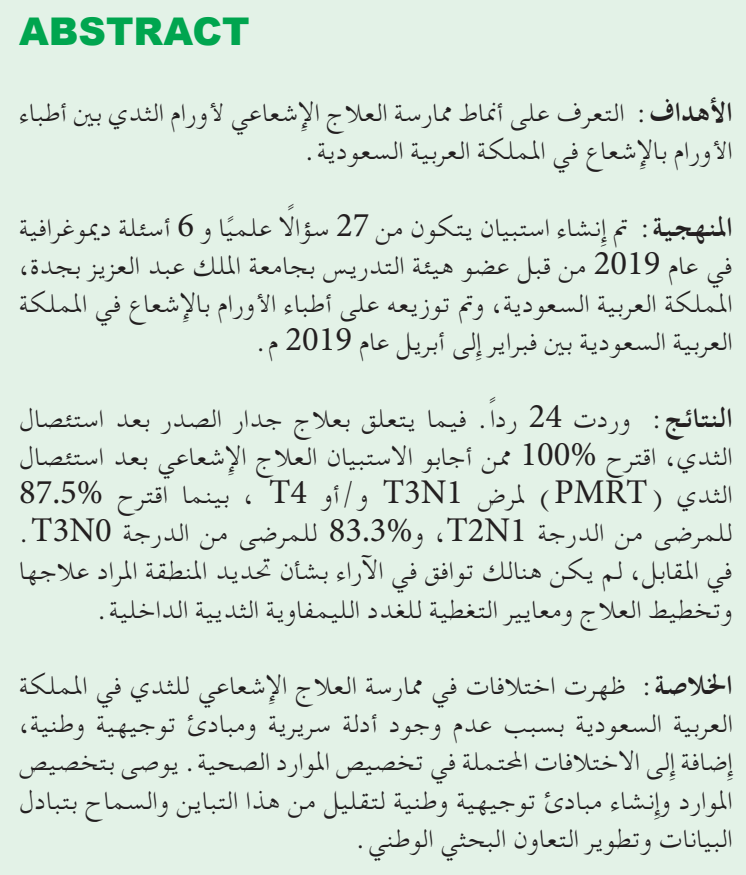

Objectives: To identify practice patterns among radiation oncologists in Saudi Arabia.

Methods: A questionnaire comprising 27 scientific questions and 6 demographic questions was created in 2019 by a faculty member at King Abdulaziz University, Jeddah, Saudi Arabia, and distributed among radiation oncologists in Saudi Arabia between February and April 2019.

Results: Twenty-four responses were received. Regarding chest wall treatment after mastectomy, $100 \%$ of the respondents offered postmastectomy radiotherapy (PMRT) for tumor stage 3 node 1 (T3N1) or T4 disease, while $87.5 \%$ offered PMRT for T2N1, and $83.3 \%$ offered PMRT for T3N0 disease. In contrast, there was a lack of consensus regarding treatment planning and coverage criteria for internal mammary lymph nodes and contouring.
Conclusion: Variations in breast radiotherapy practices in Saudi Arabia exist due to the lack of clinical evidence and national guidelines, as well as potential variations in health resources allocation. Resource allocations and the establishment of national guidelines are recommended to decrease this variation and allow for data exchange and the development of national research collaborations.

Keywords: radiotherapy, breast, Saudi Arabia, practice

Saudi Med J 2021; Vol. 42 (5): 562-569

doi: 10.15537/smj.2021.42.5.20200820

From the Department of Radiology, Faculty of Medicine, King Abdulaziz University, Jeddah, Kingdom of Saudi Arabia.

Received 28th December 2020. Accepted 15th March 2021.

Address correspondence and reprint request to: Dr. Reem K. Ujaimi, Assistant Professor, Radiation Oncologist, Department of Radiology, Faculty of Medicine, King Abdulaziz University, Jeddah, Kingdom of Saudi Arabia.E-mail: rkujaimi@kau.edu.sa

ORCID ID: https://orcid.org/0000-0002-2386-2493

B reast cancer is the most common cancer among women worldwide as well as in Saudi Arabia. ${ }^{1,2}$ In the latest cancer registry report in 2015, the median age at diagnosis was $<50$ years and the age-adjusted incidence was $22.7 / 100,000$ in the female population, and they are both most likely to increase. ${ }^{2}$ There is a paucity of data describing the stage-adjusted incidence and prevalence of different molecular subtypes of breast cancer among Saudi nationals.

A combination of surgery, hormonal therapy, chemotherapy, immunotherapy, and/or radiotherapy is used for the management of breast cancer. Adjuvant radiotherapy after lumpectomy is equivalent to mastectomy for early-stage breast cancer and improves the survival outcome of the patients. ${ }^{3}$ Even after mastectomy, adjuvant locoregional radiotherapy is correlated with improved local control and survival in high-risk patients. ${ }^{4}$ 
The indications, dosage, and treatment volumes of adjuvant locoregional radiotherapy such as adjuvant radiotherapy in node stage 1 (N1) or high-risk node-negative disease, the use of hypofractionated radiotherapy after mastectomy with or without reconstructive surgery or when treating the regional lymphatics, and the inclusion of the internal mammary (InM) chain of lymphatics in the treated volume after lumpectomy or mastectomy have been the subject of much controversy. ${ }^{5,6}$

There are also variations in the treatment planning process itself. The exact definitions of the target volumes, the use of advanced techniques, and others differ between centers and radiation oncologists. ${ }^{7}$ Those disparities may also be influenced by the availability of resources.

According to the health transformation strategy of the Saudi Vision 2030, which aims to improve the quality of services, the performance of healthcare organizations, and the delivery of safe, effective, patient-centered care ${ }^{8}$ it is important to identify these variations in practices and the issues regarding possible resource allocation. This survey aimed to identify the patterns of practices in radiotherapy for breast cancer among Saudi radiation oncologists.

Methods. In this cross-sectional study, conducted between February and April 2019, a questionnaire was distributed using official e-mail listings in the Saudi Council for Health Specialties, Jeddah, Saudi Arabia to all of the 120 registered radiation oncologists without applying any exclusion criteria, a link to the survey was also shared through the Saudi assembly of radiation oncologists. Date of birth or e-mail registration was used to confirm a single response from each radiation oncologist. Respondents to the questionnaire were asked to select "yes," indicating their consent to share their responses for research and publication purposes. The ethics board at our institution, Ref Number 63-19, approved this study and it was carried out according to principles of Helsinki Declaration.

The questionnaire, with 27 scientific and 6 demographic questions, was created using Google forms. The questions covered 6 subjects in radiotherapy for breast cancer: ductal carcinoma in situ (DCIS),

Disclosure. Author have no conflict of interests, and the work was not supported or funded by any drug company. hypofractionation, postmastectomy radiotherapy (PMRT), regional nodal irradiation (RNI), radiotherapy planning, and deep inspirational breath-hold (DIBH) techniques. These questions were selected by the author and represent controversial areas that are frequently discussed at the department and national meetings.

Statistical analyses. Simple descriptive statistical analyses were performed using IBM SPSS statistics for Windows, version 26 (IBM Corp, Armonk, NY, USA) to analyze the responses in terms of medians and standard deviations.

Results. Characteristics of the survey participants. Twenty-four (21.4\%) radiation oncologists responded to the questionnaire. The participants were $6(25 \%)$ women and $18(75 \%)$ men. Of the respondents, 9 (37.5\%) had $1-3$ years work experience and 7 (29.2\%) had $\geq 10$ years of work experience. Most respondents (38\%) were affiliated with the Ministry of Health, followed by the Ministry of Education (29\%). The majority of the respondents (83\%) underwent training in North America. Twenty-two respondents (92\%) treated breast cancer patients in their practice.

Analysis of the survey responses. Regarding DCIS, $14(58.3 \%)$ respondents chose a 2 -mm margin as the minimum acceptable margin without re-excision, whereas 7 (29.2\%) responded that anything except a positive margin was acceptable. Fifteen (62\%) respondents would provide boost radiation if the margin was less than $2 \mathrm{~mm}$. Other indications for boost radiation included young age (33\%), high-grade tumor $(25 \%)$, and positive/inoperable positive margins (12.5\%). Only one respondent chose to boost for all patients with DCIS. The above data is not tabulated.

Of the 24 radiation oncologists surveyed, $6(25 \%)$ always used hypofractionated regimens. The most common reasons for not using hypofractionation were immediate reconstruction $(45.8 \%)$, InM radiation $(25 \%)$ and nodal irradiation $(16.7 \%)$. The dose used was $40 \mathrm{~Gy} / 15 \mathrm{~F}$, although the responses were divided regarding the dose of boost radiation. More than half of the respondents would follow the exact same constraints as conventional fractionation. Table 1 shows the detailed responses of the participants.

All respondents indicated that they would offer PMRT for tumor stage 3 (T3) N1 or T4 disease, $87.5 \%$ for T2N1 disease, $83.3 \%$ for T3N0 disease, and $54.2 \%$ for high-risk N0 disease. Other reasons to offer PMRT were positive margins and a T2 larger than $4 \mathrm{~cm}$. If PMRT was indicated, $58.3 \%$ of the responders would treat the chest wall only if N0 disease was detected, whereas $20.8 \%$ would treat the chest wall and regional 
Table 1 - Features of hypofractionation regimens.

\begin{tabular}{lc}
\hline Survey questions and response(s) & $\mathbf{n}(\%)$ \\
\hline The following is a reason not to hypofractionate* & \\
Nodal irradiation, with or without InM radiation & $4(16.7)$ \\
DCIS & $3(12.5)$ \\
Postmastectomy & $2(8.3)$ \\
InM radiation & $6(25)$ \\
Immediate reconstruction & $11(45.8)$ \\
Skin involvement & $3(12.5)$ \\
None & $6(25)$ \\
Other & $2(8.3)$ \\
Dose (Gy/F) & \\
$\quad 42.4 / 16$ & $5(20.8)$ \\
$40 / 15$ & $18(75)$ \\
Other & $1(4.2)$ \\
Boost dose (Gy/F) & $12(50)$ \\
2.00 & $12(50)$ \\
2.5 & $13(54.2)$ \\
Organs at risk constraints & \\
I use the exact same constraints as conventional \\
fractionation \\
$\begin{array}{l}\text { I change the dose parameters based on the EQD2 } \\
\text { calculation }\end{array}$ \\
I follow a certain institutional or trial protocol \\
* Multiple responses allowed. InM: internal mammary, DCIS: ductal \\
$\quad$ carcinoma in situ, EQD2: equivalent dose in 2 Gy fraction \\
\hline
\end{tabular}

lymphatics in all PMRT patients. Additionally, $45 \%$ of the responders would treat the regional lymph nodes for T4 disease.

The most common practice $(58 \%)$ indicated for bolus placement was "always placing it," although for only half the course, whereas $2(8.3 \%)$ respondents indicated that they would place the bolus every day for the duration of the course and only have it removed if there was skin intolerance. The most common indication $(54.2 \%)$ for boost radiation after mastectomy was close or positive margins, and 5 (20.8\%) participants responded that they would never use boost radiation. Other reasons were, to improve coverage, inflammatory breast cancer, positive but not close margins, skin or dermal lymphatic invasion, and a thin chest wall. Table 2 shows the details of PMRT.

Fifteen (62.5\%) respondents would modify the whole-breast field to treat the regional lymph nodes for any N1 disease. In the case of patients with $\mathrm{N} 1$ disease, this percentage increased to $66.7 \%$ if there were high-risk features, $75 \%$ if an extracapsular extension was present, and $79.2 \%$ if there was inadequate axillary dissection. After a mastectomy; however, 13 (54.2\%) respondents would treat the regional lymph nodes for any N1 disease, which increased to $58.3 \%$ for N1 disease with high-risk features, $70.8 \%$ for extracapsular
Table 2 - Features of postmastectomy radiotherapy.

\begin{tabular}{lc}
\hline Survey questions and response(s) & $\mathbf{n}(\%)$ \\
\hline The following is an indication for PMRT in my & \\
practice* & \\
T3N0 & $20(83.3)$ \\
T3N1 & $24(100)$ \\
T4N any & $24(100)$ \\
T1-T2N1 & $21(87.5)$ \\
High-risk node negative & $13(54.2)$ \\
Other & $2(8.3)$ \\
PMRT volumes & \\
Chest wall only unless its N+ & $14(58.3)$ \\
Chest wall and regional nodes always & $5(20.8)$ \\
Chest wall and regional nodes for any T4 & $11(45.8)$ \\
Chest wall +/- regional nodes for high-risk node & $9(37.5)$ \\
negative & \\
Bolus placement & $2(8.3)$ \\
Always, every day, removed only for skin intolerance & $14(58.3)$ \\
Always, half of the course & $1(4.2)$ \\
For T4 only, everyday & $6(25)$ \\
For T4 only, half of the course & $1(4.2)$ \\
Other & \\
The following is an indication for scar boost after & \\
mastectomy & \\
Close or positive margin & $13(54.2)$ \\
I boost all patients & $1(4.2)$ \\
None & $5(20.8)$ \\
\hline *Multiple responses allowed PMRT: postmastectomy radiotherapy. & \\
&
\end{tabular}

extensions, and $75 \%$ for inadequate axillary dissections. Twenty-one $(87.5 \%)$ respondents would treat the regional lymph nodes for N2 disease after both lumpectomy and mastectomy. After lumpectomy, $3(12.5 \%)$ respondents would treat the regional lymph nodes for T3N0 disease without high-risk features and $11(45.8 \%)$ would treat for T3N0 disease with high-risk features. After mastectomy, 5 (20.8\%) respondents would treat the regional lymph nodes for T3N0 disease without high-risk features and $15(62.5 \%)$ would treat for T3N0 disease with high-risk features. The majority of the respondents $(95.8 \%)$ would treat the InM lymph nodes if they were radiologically positive, 2 (8.3\%) would treat them whenever the regional lymph nodes were treated, and only one (4.2\%) respondent would treat them for right-sided tumors. Fourteen (58.3\%) respondents treated InM if the tumor was N1 disease and medially located or involved more than $50 \%$ of the axillary nodes. Table 3 shows the regional nodal radiation responses.

Regarding radiotherapy planning, 21 (87.5\%) respondents would always contour the chest wall/breast 
and 23 (95.8\%) would contour the lymph nodes. However, $9(37.5 \%)$ respondents did not follow the nodal contours and used the standard field borders. Most of the respondents (83.3\%) followed the Radiation Therapy Oncology Group atlas for contouring and 12 (50\%) added a 5-mm margin for the nodal planning target volume (PTV). Seven (29\%) respondents would add PTV only for IMRT but not for 3D treatment. Internal mammary PTV responses varied, with 6 (25\%) respondents adding $3-5 \mathrm{~mm}$ but trimming from the lung and heart, 5 (20.8) adding $5 \mathrm{~mm}$ all around, and

Table 3 - Features of regional nodal irradiation (RNI).

\begin{tabular}{lc}
\hline Survey questions and response(s) & $\mathbf{n}(\%)$ \\
\hline The following is an indication for RNI after BCS and & \\
ALND* & \\
Any N1 & $15(62.5)$ \\
Macrometastatic N1 & $14(58.3)$ \\
N1 with high-risk features & $16(66.7)$ \\
N1 with inadequate axillary dissection & $19(79.2)$ \\
N1 with extracapsular extension & $18(75)$ \\
N2 & $21(87.5)$ \\
Any T3N0 & $3(12.5)$ \\
T3N0 with high-risk features & $11(45.8)$ \\
T2N0 with high-risk features & $4(16.7)$ \\
Nx & $10(41.7)$ \\
The following is an indication for RNI after MRM* & \\
Any N1 & $13(54.2)$ \\
Macrometastatic N1 & $13(54.2)$ \\
N1 with high-risk features & $14(58.3)$ \\
N1 with inadequate axillary dissection & $18(75)$ \\
N1 with extracapsular extension & $17(70.8)$ \\
N2 & $21(87.5)$ \\
Any T3N0 & $5(20.8)$ \\
T3N0 with high-risk features & $15(62.5)$ \\
T2N0 with high-risk features & $2(8.3)$ \\
Nx & $8(33.3)$ \\
The following is an indication for InM LN radiation* & \\
Radiologically positive InM node & $23(95.8)$ \\
N1 and medially located tumor & $14(58.3)$ \\
N0 and medially located tumor with certain high-risk & $3(12.5)$ \\
features & $14(58.3)$ \\
When 50\% or more of the axilla is positive & $1(4.2)$ \\
Whelume, ESTRO: European Society for Radiotherapy and Oncology, \\
InM; internal mammary, VMAT: volumetric modulated arc therapy, \\
SC: supraclavicular, ECE: extracapsular extension, T: tumor, N: node \\
\hline Whly & $2(8.3)$ \\
The definition of adequate LN dissection is & \\
8 or more & \\
10 or more & \\
15 or more & \\
\hline & \\
&
\end{tabular}

5 (20.8) adding 3-5 mm with IMRT only and without trimming. The definition of acceptable coverage for InM PTV was $80 \%$ for 7 (29.2\%) respondents, 90\% for $8(33.3 \%)$, and $95 \%$ for $4(16.7 \%)$ respondents. Four $(16.7 \%)$ respondents were only interested in clinical target volume (CTV) coverage. More than half of the respondents would prefer InM CTV to be covered by $90 \%$ of the prescription dose. The most common technique to treat InM was with modified wide tangents whenever possible at $87.5 \%$, followed by volumetric modulated arc therapy (VMAT) at $54.2 \%$. When asked for the extent of RNI after axillary dissection, 16 respondents $(68.7 \%)$ would treat the undissected axilla only with a small supraclavicular field (MA20 small field), 2 (8.3\%) would treat all axillary levels for any N1 disease, 14 (58.3\%) would treat all levels for extracapsular extension, and 17 (70.8\%) would treat for inadequate dissection. For N2 disease, $10(41.7 \%)$ would treat the dissected axilla only in cases of inadequate dissection or extensive nodal involvement and $13(54.2 \%)$ would always treat the full axilla. Table 4 shows the radiotherapy planning responses.

Ten $(41.7 \%)$ respondents would use $\mathrm{DIBH}$ techniques for all left-sided tumor patients, 8 (33.3\%) for treating InM on the left side, and 11 (45\%) when heart constraints were not acceptable. Six (25\%) radiation oncologists did not use DIBH techniques because of unavailability. Eleven $(45.8 \%)$ respondents used DIBH techniques with $3 \mathrm{D}$ treatment and 5 (20.8\%) with both 3D and VMAT/IMRT. Table 5 shows the features of DIBH.

Discussion. Breast cancer is the most common cancer among Saudi women, and the incidence rate of breast cancer continues to rise. ${ }^{9,10}$ Radiotherapy plays a major role in the management of breast cancer. However, there are worldwide variations in the practice of radiotherapy as well as in Saudi Arabia, perhaps because of the different training backgrounds of radiation oncologists. ${ }^{7}$

Ductal carcinoma in situ is not a common diagnosis in Saudi Arabia; however, national efforts to raise awareness regarding the early detection of breast cancer and improvements in health care accessibility are expected to increase the rate of DCIS diagnoses. Breast conservative surgery with adjuvant radiotherapy is the standard of care for DCIS. ${ }^{11}$ Although the management of DCIS closely follows that of early breast cancer, there are a few differences. The Society of Surgical Oncology, American Society for Radiation Oncology and American Society of Clinical Oncology published a joint consensus guideline on the margins for breast-conserving surgery 
Table 4 - Features of radiotherapy planning $(\mathrm{N}=24)$.

\begin{tabular}{|c|c|c|}
\hline Survey question & Response & n $(\%)$ \\
\hline \multirow[t]{3}{*}{ I contour chest wall/breast } & Always & $21(87.5)$ \\
\hline & Never & $1(4.2)$ \\
\hline & Only when treating with IMRT & $2(8.3)$ \\
\hline \multirow[t]{3}{*}{ I contour nodal CTV } & Always & $23(95.8)$ \\
\hline & Never & $0(0)$ \\
\hline & Only when treating with IMRT & $1(4.2)$ \\
\hline \multirow[t]{4}{*}{ If nodal CTV was contoured* } & I adjust the field border/ shielding accordingly & $16(66.7)$ \\
\hline & $\begin{array}{l}\text { I follow the standard field borders and use the contours for } \\
\text { reference only }\end{array}$ & $9(37.5)$ \\
\hline & I don't contour nodal CTV anyway & $0(0)$ \\
\hline & Other & $0(0)$ \\
\hline \multirow[t]{3}{*}{ My LN CTV follows } & RTOG atlas & $20(83.3)$ \\
\hline & ESTRO atlas & $2(8.3)$ \\
\hline & Other & $2(8.3)$ \\
\hline \multirow[t]{5}{*}{ My LN PTV } & Is $3 \mathrm{~mm}$ & $3(12.5)$ \\
\hline & Is $5 \mathrm{~mm}$ & $12(50)$ \\
\hline & Is equal to my CTV & $2(8.3)$ \\
\hline & $\begin{array}{l}\text { Is technique dependent, I add 3-5 mm when using IMRT but } \\
\text { not with 3D }\end{array}$ & $7(29.2)$ \\
\hline & Other & $0 .(0)$ \\
\hline \multirow[t]{7}{*}{ InM PTV } & Is equal to my CTV & $2(8.3)$ \\
\hline & $5 \mathrm{~mm}$ all around & $5(20.8)$ \\
\hline & $3 \mathrm{~mm}$ all around & $3(12.5)$ \\
\hline & 3 or $5 \mathrm{~mm}$, but trimmed from lung/heart & $6(25)$ \\
\hline & $\begin{array}{l}\text { Is technique dependent, I add } 3-5 \mathrm{~mm} \text { when using IMRT but } \\
\text { not with } 3 \mathrm{D} \text {, and I DO NOT trim from lung or heart }\end{array}$ & $5(20.8)$ \\
\hline & $\begin{array}{l}\text { Is technique dependent, I add } 3-5 \mathrm{~mm} \text { when using IMRT but } \\
\text { not with } 3 \mathrm{D} \text {, and I DO trim from lung or heart }\end{array}$ & $3(12.5)$ \\
\hline & Other & $0(0)$ \\
\hline \multirow[t]{4}{*}{ Acceptable InM PTV coverage is } & $80 \%$ of prescription & $7(29.2)$ \\
\hline & $90 \%$ of prescription & $8(33.3)$ \\
\hline & $95 \%$ of prescription & $4(16.7)$ \\
\hline & I only care about CTV coverage & $4(16.7)$ \\
\hline \multirow[t]{3}{*}{ Acceptable InM CTV coverage } & $80 \%$ of prescription & $6(25)$ \\
\hline & $90 \%$ of prescription & $13(54.2)$ \\
\hline & $95 \%$ of prescription & $5(20.8)$ \\
\hline \multirow[t]{6}{*}{ Technique used when treating $\operatorname{InM}^{*}$} & Modified wide tangents whenever possible & $21(87.5)$ \\
\hline & Direct electron field matching photon tangents whenever possible & $4(16.7)$ \\
\hline & Step and shoot IMRT & $6(25)$ \\
\hline & VMAT & $13(54.2)$ \\
\hline & Tomotherapy & $4(16.7)$ \\
\hline & Other & $0(0)$ \\
\hline \multirow[t]{6}{*}{ RNI after axillary dissection* } & $\begin{array}{l}\text { For any N1 I treat as per MA20 (small SC field encompassing } \\
\text { axilla 3-SC) }\end{array}$ & $16(66.7)$ \\
\hline & For N1+ ECE I treat the full axilla+SC+/-InM & $14(58.3)$ \\
\hline & For any N1 I treat the full axilla+SC+/-InM & $2(8.3)$ \\
\hline & For $\mathrm{N} 1+$ inadequate dissection I treat the full axilla $+\mathrm{SC}+/-\mathrm{InM}$ & $17(70.8)$ \\
\hline & $\begin{array}{l}\text { For N2 I always treat the dissected axilla +SC+/- InM (large } \\
\text { MA20 SC field) }\end{array}$ & $13(54.2)$ \\
\hline & $\begin{array}{l}\text { For N2 I treat the dissected axilla only in cases of inadequate } \\
\text { dissection or extensive nodal involvement }\end{array}$ & $10(41.7)$ \\
\hline
\end{tabular}

*Multiple responses allowed. CTV: clinical target volume, IMRT: intensity modulated radiotherapy, LN: lymph node, RTOG: Radiation Therapy Oncology Group, PTV: planning target volume, ESTRO: European Society for Radiotherapy and Oncology, InM: internal mammary, VMAT: volumetric modulated arc therapy, RNI: regional nodal irradiation, SC: supraclavicular, ECE: extracapsular extension 
Table 5 - Features of DIBH techniques.

\begin{tabular}{|c|c|}
\hline Survey questions and response(s) & n $(\%)$ \\
\hline \multicolumn{2}{|l|}{ I use DIBH technique(s) } \\
\hline With 3D & $11(45)$ \\
\hline With IMRT/VMAT & $1(4.2)$ \\
\hline With both & $5(20.8)$ \\
\hline I do not use it & $7(29.2)$ \\
\hline \multicolumn{2}{|l|}{ I use DIBH technique(s)* } \\
\hline For all left-sided patients & $10(41.7)$ \\
\hline When treating InM on the left side & $8(33.3)$ \\
\hline When heart constraints are not acceptable & $11(45.8)$ \\
\hline $\begin{array}{l}\text { At our department we have a protocol for } \\
\text { screening patients who could benefit from it }\end{array}$ & $2(8.3)$ \\
\hline $\begin{array}{l}\text { I do not use it because it is not available at our } \\
\text { center }\end{array}$ & $6(25)$ \\
\hline Other & $1(4.2)$ \\
\hline \multicolumn{2}{|l|}{ If you chose other above, please specify } \\
\hline \multicolumn{2}{|l|}{$\begin{array}{l}\text { Any side with InMN, also if liver is located high } \\
\text { in chest and occasionally with right side SCV } \\
\text { field if very young patient }\end{array}$} \\
\hline \multicolumn{2}{|l|}{ I do not use DIBH technique(s) because* } \\
\hline $\begin{array}{l}\text { The accessories are not available at my center, I } \\
\text { would love to acquire them }\end{array}$ & $7(53.8)$ \\
\hline $\begin{array}{l}\text { It takes a long time in the machine; we cannot } \\
\text { afford it }\end{array}$ & $3(23.1)$ \\
\hline I am satisfied with my treatment without it & $5(38.5)$ \\
\hline No reason, just never thought of using it & $1(7.7)$ \\
\hline \multicolumn{2}{|c|}{$\begin{array}{l}\text { *Multiple responses allowed. DIBH: deep inspirational breath } \\
\text { hold, IMRT: intensity modulated radiotherapy, VMAT: volumetric } \\
\text { modulated arc therapy, InM: internal mammary, InMN: internal } \\
\text { mammary nodes, SCV: supraclavicular }\end{array}$} \\
\hline
\end{tabular}

with whole-breast irradiation in DCIS, indicating $2 \mathrm{~mm}$ as the minimum acceptable margin. However, clinical judgment is required to decide on the necessity and suitability of re-excision. ${ }^{12}$ Boost radiotherapy to the surgical bed is not widely adopted for DCIS because trials on the role of boost radiotherapy largely focus on invasive cancer. ${ }^{7}$ Nevertheless, there is an evidence to suggest an improvement in local control with the use of tumor bed boost radiotherapy in DCIS. ${ }^{13}$

Hypofractionation at a dose of $40 / 15$ or $42.5 / 16$ is the standard of care after breast conservative surgery. ${ }^{14}$ However, the use of hypofractionation for locoregional treatment as well as in the setting of PMRT with or without immediate reconstruction is controversial. ${ }^{7}$ The Danish and Canadian postmastectomy landmark trials that revealed survival advantage following the addition of adjuvant radiation after mastectomy have actually delivered hypofractionated regimens.. ${ }^{15,16}$ In the United Kingdom (UK), it is standard practice to offer hypofractionated radiotherapy to all patients in the adjuvant setting. ${ }^{17}$ The Canadians are currently recruiting for a phase 3 randomized trial of standard versus hypofractionated radiotherapy after mastectomy with or without reconstruction. ${ }^{18}$ The Study of Radiation Fractionation on Patient Outcomes After Breast REConstruction (FABREC) is a phase 2 trial that is recruiting and investigating whether hypofractionated radiotherapy to the chest wall and the regional lymph nodes is superior to standard fractionation in the reconstructed breast. ${ }^{19}$ Wang et al ${ }^{20}$ found hypofractionated radiotherapy to be non-inferior to standard fractionation in the setting of T3-T4 or N2 disease.

The benefits of PMRT are controversial; nevertheless, there is a strong consensus among Saudi radiation oncologists regarding using PMRT. Postmastectomy radiotherapy is indicated for advanced primary or nodal disease. ${ }^{16}$ However, the value of PMRT for N1 disease or high-risk nodal negative disease is in question, particularly in the better systemic therapy setting. ${ }^{6,21}$ Two randomized phase 3 trials are underway to clarify the value of PMRT: the UK Selective Use of Postoperative Radiotherapy After Mastectomy (SUPREMO) trial, which is looking for the role of PMRT in high-risk node-negative patients and $\mathrm{N}$ disease ${ }^{22}$ and the Tailor RT trial, a Canadian trial investigating the predictive value of low-risk oncotype DX recurrence scores in N1 patients. ${ }^{23}$ The use of a bolus with PMRT is another vague area with conflicting evidence. Some departments use a bolus for all patients, whereas others use it only in patients with skin involvement. Daily bolus on alternate days or half the bolus on consecutive days are 2 different practices. ${ }^{7}$ Some authors reported a higher risk of recurrence when a bolus is not used, whereas others demonstrated similar local control with the routine omission of the bolus when no skin involvement was observed. ${ }^{24,25}$ Variations in the bolus placement practice are, therefore, expected.

The majority of postmastectomy trials as well as trials of locoregional irradiation after breast-conserving surgery included comprehensive nodal radiotherapy with the inclusion of the InM chain of lymphatics. ${ }^{6,16}$ Nonetheless, indications for RNI and radiation volumes are still controversial. Excluding the dissected axilla (or intentionally not including it) from the radiotherapy field in the adequate axillary dissection setting, the definition of which is debatable, is clearly not a standard practice among responders. Neither is the inclusion of the InM lymph nodes, reflecting worldwide variation in practices. ${ }^{7}$ Radiation to the InM chain recently gained interest, particularly with the technique modifications that allow for cardiac and lung dose reduction. ${ }^{6}$

Treatment planning volumes and techniques vary among radiation oncologists not only nationwide, but 
worldwide, and is the area with the most variation among respondents in this survey, particularly concerning the InM volumes and coverage criteria. Intensity modulated radiotherapy is an acceptable practice in some centers while standard fields remain in others. ${ }^{7}$ Several contouring guidelines have been published. ${ }^{26,27}$ However, standard fields do not adequately cover the recommended targets, and the decision to expand the field to cover these targets or acceptance of inadequate coverage should be cautiously individualized. In addition, InM recurrences have been reported outside the recommended contours. ${ }^{28}$ There is no consensus regarding the definition of acceptable coverage for the InM lymph nodes, and careful modification of the recommended volume to ensure adequate coverage of the targets should be balanced against the potential toxicity of radiotherapy. ${ }^{28-30}$

The DIBH technique for patients with left-sided breast cancer is widely adopted. ${ }^{7}$ Limitations to the routine use of DIBH techniques in certain centers are the cost and significant resource commitment required, and our study responses revealed that $25 \%$ of the respondents would not use DIBH techniques because of the lack of availability. ${ }^{31}$

At the time of writing this manuscript, the world had been suffering from the effects of the coronavirus disease (COVID-19) pandemic. Many radiotherapy centers around the world adopted measures to reduce patient and staff exposure to potential infections. Although some measures were not based on level one evidence, the severity of the situation has mandated bold measures. These measures included omitting radiotherapy when deemed of little or no definitive benefit in the adjuvant setting or reducing the number of fractions when deemed acceptable. For breast cancer, in particular, radiotherapy after lumpectomy for nodenegative, early-stage, and hormone-positive disease can be omitted. ${ }^{32}$ Additionally, an expedited review and publication of the 5-year results of the FAST-forward trial investigating 5 daily fractions of 5.7 Gy in the adjuvant setting coincided with the emerging need for hypofractionation and was quickly adopted, at least for early disease and during the current global pandemic situation. ${ }^{32,33}$

This study is an effort to look into the practice of radiation oncologists in Saudi Arabia. I have addressed almost all of the controversies related to breast radiotherapy. However, I acknowledge the inherent weakness of web-based surveys, such as the lack of accountability and accuracy and the association with a failure to personally explain confusing questions or answer choices. Additionally, the relatively small and underrepresented number of respondents in this survey may be overcome in the future by expanding the inclusion criteria for the study participants.

In conclusion, radiotherapy practice variations among Saudi radiation oncologists echo international variations in many aspects due to the lack of strong evidence and availability of resources. Resource allocation, particularly for DIBH techniques, and the establishment of national guidelines, are recommended to decrease the disparity in radiotherapy practice and promote the exchange of data and national research collaborations. Prospective follow-up data collection at the national level should be initiated to identify possible dissimilarities in our patient characteristics as well as the potential need for treatment intensification, particularly in areas of international variations.

Future research is required to answer the questions raised and expand the study areas to include radiation oncologists from the Gulf, Arab, and Middle Eastern countries.

Acknowledgment. I extend my appreciation to Dr. Zayd Jastaniah, MD, Dr. Hanadi Habibullah, MD, FRCPC, and Dr Taghreed Al. Hendi, MD, FRCPC for having served as scientific advisors for this paper. I would also like to thank Editage (www.editage.com) for English language editing.

\section{References}

1. McGuire S. World Cancer Report 2014. Geneva, Switzerland: World Health Organization, International Agency for Research on Cancer, WHO Press, 2015. Adv Nutr 2016; 7: 418-419.

2. Asiri S, Asiri A, Ulahannan S, Alanazi M, Humran A, Hummadi A. Incidence rates of breast cancer by age and tumor characteristics among saudi women: recent trends. Cureus 2020; 12: e6664.

3. van Maaren MC, de Munck L, de Bock GH, Jobsen JJ, van Dalen T, Linn SC, et al. 10 year survival after breast-conserving surgery plus radiotherapy compared with mastectomy in early breast cancer in the Netherlands: a population-based study. Lancet Oncol 2016; 17: 1158-1170.

4. Recht A, Comen EA, Fine RE, Fleming GF, Hardenbergh $\mathrm{PH}, \mathrm{Ho}$ AY, et al. Postmastectomy radiotherapy: An American Society of Clinical Oncology, American Society for Radiation Oncology, and Society of Surgical Oncology focused guideline update. J Clin Oncol 2016; 6: e219-e234.

5. Duane FK, McGale P, Teoh S, Mortimer C, Broggio J, Darby $\mathrm{SC}$, et al. International variation in criteria for internal mammary chain radiotherapy. Clin Oncol 2019; 31: 453-461.

6. Duma MN. An update on regional nodal irradiation: indication, target volume delineation, and radiotherapy techniques. Breast Care 2020; 15:128-135.

7. Nguyen K, Mackenzie P, Allen A, Dreosti M, Morgia M, Zissiadis $\mathrm{Y}$, et al. Breast interest group faculty of radiation oncology: Australian and New Zealand patterns of practice survey on breast radiotherapy. J Med Imaging Radiat Oncol 2017; 61: 508-516. 
8. Saudi Vision 2030. Saudi National Transformation Program, 2016. Saudi Arabia Government [Updated 2021; Cited 2020 November 16]. Available from: https://vision2030.gov.sa/en

9. Althubiti MA, Nour Eldein MM. Trends in the incidence and mortality of cancer in Saudi Arabia. Saudi Med J 2018; 39: 1259-1263.

10. Almutlaq BA, Almuazzi RF, Almuhayfir AA, Alfouzan AM, Alshammari BT, AlAnzi HS, et al. Breast cancer in Saudi Arabia and its possible risk factors. J Cancer Policy 2017; 12: 83-89.

11. Smith BD, Bellon JR, Blitzblau R, Freedman G, Haffty B, Hahn C, et al. Radiation therapy for the whole breast: executive summary of an American Society for Radiation Oncology (ASTRO) evidence-based guideline. Pract Radiat Oncol 2018; 8: $145-152$.

12. Morrow M, Van Zee KJ, Solin LJ, Houssami N, ChavezMacGregor M, Harris JR, et al. Society of Surgical OncologyAmerican Society for Radiation Oncology-American Society of Clinical Oncology consensus guideline on margins for breastconserving surgery with whole-breast irradiation in ductal carcinoma in situ. J Clin Oncol 2016; 23: 3801-3810.

13. Moran MS, Zhao Y, Ma S, Kirova Y, Fourquet A, Chen P, et al. Association of radiotherapy boost for ductal carcinoma in situ with local control after whole-breast radiotherapy. JAMA Oncol 2017; 3: 1060-1068.

14. Gupta A, Ohri N, Haffty BG. Hypofractionated radiation treatment in the management of breast cancer. Expert Rev Anticancer Ther 2018; 18: 793-803.

15. Laurberg T, Tramm T, Nielsen T, Alsner J, Nord S, Myhre $S$, et al. Intrinsic subtypes and benefit from postmastectomy radiotherapy in node-positive premenopausal breast cancer patients who received adjuvant chemotherapy-results from two independent randomized trials. Acta Oncol (Madr) 2018; 38-43.

16. Ejlertsen B, Offersen BV, Overgaard J, Christiansen P, Jensen $\mathrm{MB}$, Kroman N, et al. Forty years of landmark trials undertaken by the Danish Breast Cancer Cooperative Group (DBCG) nationwide or in international collaboration. Acta Oncol (Madr) 2018; 57: 3-12.

17. The Royal College of Radiologist. Postoperative radiotherapy for breast cancer: UK consensus statements. [Updated 2016 November; Accessed 2020 December 16]. Available from: https://www.rcr.ac.uk/system/files/publication/field_ publication_files/bfco2016_breast-consensus-guidelines.pdf

18. ClinicalTrials.gov [Internet]. Identifier NCT03414970, Hypofractionated radiation therapy after mastectomy in preventing recurrence in patients with stage IIa-IIIa breast cancer. [Updated 2018 January 30. Cited 2020 December 16]. Available from: https://Clinicaltrials.Gov/Show/Nct03414970

19. ClinicalTrials.gov. Study of radiation Fractionation on patient outcomes after breast REConstruction (FABREC) for invasive breast carcinoma. Identifier NCT03422003. [Updated 2018 February 5; Accessed 2020 December 16]. Available from: https://Clinicaltrials.Gov/Show/Nct03422003.

20. Wang SL, Fang H, Song YW, Wang WH, Hu C, Liu YP, et al. Hypofractionated versus conventional fractionated postmastectomy radiotherapy for patients with high-risk breast cancer: a randomised, non-inferiority, open-label, phase 3 trial. Lancet Oncol 2019; 20: 352-360.
21. Kim YJ, Park W, Ha B, Park B, Joo J, Kim TH, et al. Postmastectomy radiotherapy in patients with pT1-2N1 breast cancer treated with taxane-based chemotherapy: A retrospective multicenter analysis (KROG 1418). Cancer Res Treat 2017; 49: 927.

22. Velikova G, Williams LJ, Willis S, Dixon JM, Loncaster J, Hatton $\mathrm{M}$, et al .Quality of life after postmastectomy radiotherapy in patients with intermediate-risk breast cancer (SUPREMO): 2-year follow-up results of a randomised controlled trial. Lancet Oncol 2018; 19: 1516-1529.

23. Parulekar WR, Berrang T, Kong I, Rakovitch E, Theberge V, Gelmon KA, et al. Cctg MA.39 tailor RT: a randomized trial of regional radiotherapy in biomarker low-risk node-positive breast cancer (NCT03488693). J Clin Oncol 2019; 37: TPS602.

24. Boulle G, Saint-Martin C, De La Lande B, Laki F, Bidoz NF, Berger F, et al. Photons without bolus versus electrons with bolus after upfront mastectomy without Immediate reconstruction in breast cancer patients. Int J Radiat Oncol Biol Phys 2019; 104: 877-884.

25. Nichol A, Raman S, Truong P, Lovedeep G, Speers C, Tran E, et al. The effect of bolus on local control for patients treated with mastectomy and adjuvant radiotherapy. Int J Radiat Oncol 2019; 105: S9.

26. Borm KJ, Voppichler J, Düsberg M, Oechsner M, Vag T, Weber W, et al. FDG/PET-CT-Based lymph node atlas in breast cancer patients. Int J Radiat Oncol Biol Phys 2019; 103: 574-582.

27. Ujaimi R, Awad N, Hasan Z, Abbas N, Baageel W, Khayyat S et al. Internal mammary lymph node volume: what radiation dose is received with modified wide tangents? Int $j$ pharm phytopharm res 2020; 10: 76-81.

28. Jethwa KR, Kahila MM, Hunt KN, Brown LC, Corbin KS, Park SS, et al. Delineation of internal mammary nodal target volumes in breast cancer radiation therapy. Int J Radiat Oncol Biol Phys 2017; 97: 762-769.

29. Meattini I, Guenzi M, Fozza A, Vidali C, Rovea P, Meacci F, et al. Overview on cardiac, pulmonary and cutaneous toxicity in patients treated with adjuvant radiotherapy for breast cancer. Breast Cancer 2017; 24: 52-62.

30. Lewis GD, Farach A. Cardiovascular toxicities of radiation therapy. Methodist Debakey Cardiovasc J 2019; 15: 274-281.

31. Chatterjee S, Chakraborty S, Moses A, Nallathambi C, Mahata A, Mandal S, et al. Resource requirements and reduction in cardiac mortality from deep inspiration breath hold (DIBH) radiation therapy for left sided breast cancer patients: A prospective service development analysis. Pract Radiat Oncol 2018; 8: 382-387.

32. Simcock R, Thomas TV, Estes C, Filippi AR, Katz MA, Pereira IJ, et al. COVID-19: global radiation oncology's targeted response for pandemic preparedness. Clin Transl Radiat Oncol 2020; 22: 55-68.

33. Brunt AM, Haviland JS, Wheatley DA, Sydenham MA, Alhasso A, Bloomfield DJ, et al. Hypofractionated breast radiotherapy for 1 week versus 3 weeks (FAST-Forward): 5-year efficacy and late normal tissue effects results from a multicenter, non-inferiority, randomized, phase 3 trial. Lancet 2020; 395: 1613-1626. 